\title{
DIMENSÕES EDUCATIVAS NÃO FORMAIS E INFORMAIS DAS PRÁTICAS CULTURAIS JUVENIS NA CIDADE
}

\author{
Luís Antonio Groppo \\ Enzo Michel Felipe Correia dos Santos Goussain \\ Universidade Federal de Alfenas (UNIFAL), \\ Alfenas, Minas Gerais, Brasil
}

\begin{abstract}
ResUMO: O artigo sistematiza dados colhidos em pesquisa de campo - com observações e entrevistas - a respeito de práticas culturais de jovens das camadas populares em dois projetos socioeducativos e três grupos informais, em um município do Sul de Minas Gerais. Trata da dimensão educativa destas práticas, em especial dos seus objetivos e metodologias, com base nas noções de educação não formal e educação informal. Constata-se a riqueza das práticas culturais juvenis, a diversidade de referências e a força das culturas negras, com o Hip Hop e as artes afro-brasileiras. Também, a combinação entre estratégias mais ou menos formais de educação e a criação de circuitos entre projetos socioeducativos e coletivos juvenis.

Palavras-chave: Educação não formal. Educação informal. Cultura juvenil. Projetos socioeducativos. Hip Hop.
\end{abstract}

\section{Culturas JUVENIS E CULTURA POPULAR}

Neste artigo, buscamos observar e interpretar as práticas culturais dos sujeitos populares realmente existentes, considerando a "cultura popular" como as experiências vividas concretamente pelas camadas populares ou classes trabalhadoras. Entre estes sujeitos, os jovens das classes trabalhadoras dos campos e das cidades. 
Aqui, neste texto, trataremos de algumas destas práticas de jovens de uma cidade do Sul de Minas Gerais. Como se trata de uma cidade pequena em comparação com as grandes metrópoles do país, em uma região onde é ainda muito forte a economia agrária, haveria de se esperar destas práticas dos jovens populares, talvez, muito daquela permanência das tradições imemoriais, do isolamento "comunitário" ou de referências exclusivamente nativas, que marcam algumas noções de cultura e cultura popular (EAGLETOWN, 2003). Contudo, encontramos uma versão própria da bricolagem que tantos estudos têm registrado sobre as culturas juvenis nas metrópoles, despreocupada com o caráter puro, tradicional, comunitário ou autóctone das suas práticas (HALL; JEFFERSON, 1982; CRUZ, 2000).

Há mesmo um intercurso entre distintos grupos de jovens, por vezes partícipes de diferentes classes sociais, já que se constatou grande influência dos estudantes universitários (muitos deles, vindos de fora da região) nas práticas culturais dos jovens das camadas trabalhadoras (que, em geral, não são universitários). Estas práticas, enfim, estão a serviço de diferentes necessidades sociais, podendo operar como canal de expressão de identidades, de cultivo do corpo, da busca do prazer e do lúdico e até como forma de trabalho ou sobrevivência (PAIS, 1990; DAYRELL, 2002; SILVA, 2012).

As práticas culturais juvenis na cidade são tão fortes que têm servido como conteúdo e mote para projetos socioeducativos destinados a adolescentes e jovens, com intenções de intervir em problemas sociais que afetam camadas populares. Ao mesmo tempo, em conjunto ou em paralelo a estes projetos, algumas iniciativas têm buscado organizar estas práticas por meio de coletivos informais mantidos pelos próprios jovens. Uns e outros têm evidenciado, enfim, o que é tema deste dossiê, interessantes estratégias educativas ou formativas, por meio das quais as práticas são reproduzidas e ganham novos adeptos. Estas estratégias são diversas vezes surpreendentes, inclusive pela pouca consciência que os próprios formadores têm do caráter educativo delas. Evidenciar este caráter formativo e educativo das práticas culturais juvenis na cidade nos parece ser a principal justificativa deste trabalho.

EDUCAÇÃO NÃO FORMAL E EDUCAÇÃO INFORMAL

Consideramos relevante interpretar as dimensões educativas das práticas culturais juvenis com base nas categorias de educação informal e não formal. Partimos, contudo, não das noções que se referem aos conteúdos so- 
ciais e históricos precisos, mas sim como perspectivas que se manifestam em tipos ideais ou puros, no sentido weberiano. Max Weber (1979) considerava que os pesquisadores sociais precisavam analisar os dados empíricos munidos de parâmetros (conceitos ou tipos ideais) para orientar a sua interpretação das ações humanas. Os tipos ideais não são a redução da realidade à sua suposta essência, mas, sim, instrumentos que permitem a compreensão da realidade social, já que possibilitam aferir quais são as principais tendências dos sujeitos e grupos ao agirem socialmente. Deste modo, referenda-se a posição de Alfonso (2001), segundo a qual a educação informal e a educação não formal sempre existiram e conviveram com a educação formal ou escolar.

Considerando tal posição, lembramos que, tradicionalmente, distinguiram-se na sociologia da educação duas categorias do educar: a educação escolar e a educação familiar; também conhecidas como educação formal e informal. A educação formal foi e é relacionada às instituições escolares. Já a educação informal é tratada como "[...] toda gama de aprendizagens que realizamos (tanto no papel de ensinantes como de aprendizes) que acontece sem que nos demos conta. Acontece ao longo da vida, constitui um processo permanente e contínuo e não previamente organizado". (PARK; FERNANDES; CARNICEL, 2007, p. 127). Estas aprendizagens, que se dão no cotidiano, e não apenas no universo familiar, configuram-se como um rico e complexo repertório de saberes: “[...] percepção gestual, moral, de comportamentos provenientes de meios familiares, de amizade, de trabalho, de socialização, midiática, nos espaços públicos em que repertórios são expressos e captados de formas assistemáticas" (PARK; FERNANDES; CARNICEL, 2007, p. 127).

Mas se o reconhecimento da educação informal como categoria relevante para as pesquisas sobre educação já é tradicional, o mesmo não acontece com as práticas educativas não formais. O reconhecimento delas é mais recente e, justamente por isto, envolto em polêmicas sobre qual seria mesmo a sua melhor denominação, com propostas tais como educação não formal, educação não escolar, educação social, educação comunitária, pedagogia social, educação popular, entre outros (GROPPO et al., 2013).

O termo educação não formal teve grande relevância no reconhecimento desta terceira categoria de práticas educacionais no Brasil a partir dos anos 1990. Alfonso assim distingue o formal do não formal:

Por educação formal entende-se o tipo de educação organizada com uma determinada sequência (prévia) e proporcionada pelas escolas, enquanto que a designação não-formal, embora obedeça a uma estrutura e a uma 
organização (distintas, porém das escolas) e possa levar a uma certificação (mesmo que não seja essa a finalidade), diverge ainda da educação formal no que respeita a não-fixação de tempos e locais e a flexibilidade na adaptação aos conteúdos de aprendizagem a cada grupo concreto. (apud PARK; FERNANDES; CARNICEL, 2007, p. 131).

A educação não formal tem como características: intencionalidade, caráter não obrigatório, mistura de idades, flexibilidade de tempos e espaços, orientação para as necessidades dos grupos envolvidos, não apresenta hierarquização, não visa certificação e acontece por meio de metodologias variadas (GARCIA, 2007).

Como categoria ideal típica, a educação não formal pode caracterizar situações diversas de ensino-aprendizagem que não se prendem à contemporaneidade, situações que aparecem ao lado da educação informal e que muitas vezes precedem à generalização da educação escolar no mundo moderno. Weber (1979) traz exemplos da formação de letrados chineses, sacerdotes, guerreiros e artesãos (RODRIGUES, 2004). Podem ser citadas também a educação popular na América Latina e a educação nos movimentos sociais. Enfim, recentemente, descreve as práticas educativas do chamado "terceiro setor" ou "organizações da sociedade civil", tais como organizações não governamentais (ONGs), fundações empresariais e projetos socioeducativos.

Certamente, reconhecemos outras possibilidades contidas na vasta produção nacional e internacional sobre o tema, como as abordagens focadas nos conteúdos da educação não formal, ou a interpretação de que a "forma escolar" avança sobre espaços educativos não escolares. ${ }^{1}$ Contudo, pensamos ser promissor o uso destas duas categorias, na qualidade de tipos ideais, para pensar as práticas culturais dos jovens que pesquisamos. A princípio, a educação não formal, para tratar das práticas culturais ensinadas para e com os jovens em projetos socioeducativos. Em seguida, a educação informal, para tratar do modo como são reproduzidas as práticas no interior de coletivos auto-organizados pelos jovens na cidade.

\section{A PESQUISA DE CAMPO}

A pesquisa de campo começou com um levantamento dos principais projetos e instituições que desenvolvem práticas socioeducativas para adolescentes e jovens no município sul-mineiro, destacando aqueles cujas práticas tinham como conteúdos a cultura e os esportes. Entre elas, duas 
organizações fazem uso de práticas culturais juvenis em suas atividades educativas: o Projeto Social e o Movimento Negro. ${ }^{2}$

O Projeto Social é uma iniciativa sem fins lucrativos, bastante recente, iniciada em 2015, que busca oferecer atividades educativas e culturais para as crianças e jovens em situação de vulnerabilidades sociais e econômicas, com os objetivos de desenvolvimento artístico, cultural, convívio humano e, segundo o Projeto, de afastá-los da "ociosidade" e dos riscos do envolvimento com as drogas e com outros atos ilícitos. O projeto oferece aulas gratuitas de artes marciais (Capoeira, Jiu Jitsu e Muay Thai), de dança (Breakdance e Zumba) e de algumas modalidades esportivas (Futebol e Rugby) e funciona todos os dias da semana, à noite, por meio de voluntários que dirigem o projeto e são educadores.

O Movimento Negro, além de todas as ações de valorização da cultura afro e de conscientização sobre os direitos da população negra, também oferece uma série de práticas educativas ligadas à cultura popular, à música e a algumas modalidades esportivas para crianças e jovens da cidade. Entre as ações desenvolvidas, destacam-se as oficinas de percussão e música afro (em especial a Mojuba), de dança (Jongo e Maculelê), as aulas de artes marciais (Capoeira, Tae Kwon-do e Karatê), Ginástica e Xadrez.

Contudo, inclusive graças a contatos pessoais, a pesquisa de campo permitiu o conhecimento de alguns grupos juvenis informais, ou coletivos fluidos (nos termos de SILVA; CASTRO, 2013), que desenvolvem certas práticas esportivas e culturais e que também podem ser consideradas como formas alternativas de educação, como se verá. Tratam-se dos grupos dos Skatistas, dos B.boys e dos Rappers, os dois últimos constituintes da cultura de rua intitulada Hip Hop. São práticas comuns da contemporaneidade urbana dos grandes centros e que cada vez mais estão presentes nas pequenas cidades do país, como é o caso do município sul-mineiro. Dentre estes três grupos, os skatistas são os únicos que apresentam uma associação formalizada, a Associação dos Skatistas.

Para o contato com estes três grupos juvenis, contamos com o apoio de estudantes da universidade pública do município, que são organizadores de um evento cultural que reúne inúmeros artistas dos mais diferentes segmentos do Hip Hop. Este evento conta com grande participação de entidades do município, de apoiadores dos eventos culturais e de outros discentes universitários, tanto na sua organização quanto na participação, oferecendo oficinas, palestras e apoio para os envolvidos. O evento é gratuito e acontece em uma das praças centrais do município da cidade, uma vez por semestre. 
Escolhidos os projetos e os atores para a investigação, o autor-pesquisador foi ao encontro de seus responsáveis para combinar as observações e as entrevistas. Em todos os casos se realizaram pelo menos três visitas: a primeira, para estabelecer os contatos com as iniciativas e com seus dirigentes e educadores; a segunda, para fazer as observações das práticas educativas; e a terceira, para realizar as entrevistas. Ressaltamos que as observações, inclusive durante as entrevistas, ou seja, o que se pode captar pelo "olhar" e pelo "ouvir" - aspectos essenciais da observação participante (OLIVEIRA, 2006) - foram de grande valia. Assim, fez-se registro de vasta gama de dados, em diário de campo, em gravações de aúdio e vídeo e fotografias, os quais fundamentam as interpretações deste e dos próximos itens do artigo.

\section{Projetos socioeducativos e grupos CUlturais}

Juliano é gestor do Projeto Social, tem 24 anos, oriundo de uma família de classe trabalhadora, é vice-diretor e também educador do projeto, atuando como professor de artes marciais nas modalidades capoeira, Muay Tay e Jiu Jitsu. Realizamos a entrevista no próprio barracão do projeto, um espaço de mais ou menos $150 \mathrm{~m}^{2}$ e que fica localizado em um bairro residencial de classe média.

Juliano diz acreditar no poder transformador e emancipador das práticas esportivas e culturais para as juventudes do município como forma de "ocupação do tempo e da mente" nos períodos de "maior risco", ou seja, no tempo em que os jovens não estão na escola, a fim de afastá-los da criminalidade e das drogas. Afirma, ainda, que o objetivo do programa é oferecer um "ambiente saudável, seguro e repleto de atividades" para que os jovens possam descobrir aptidões, talentos e "ensinamentos que possam ser levados para a vida toda". É exatamente isto que ele busca passar para seus alunos quando está no tatame. Entre a instrução de uma técnica marcial e outra, aos seus 30 educandos, sempre ressalta a importância do respeito e da postura dos jovens perante a família, os mais velhos e a sociedade como um todo.

Juliano nos diz que, ao lado da dificuldade natural de se conseguir mais voluntários para dar aulas de modalidades diversas para os jovens, outro grande desafio é conseguir parceiros e colaboradores que possam ajudar a custear os gastos do estabelecimento, já que a iniciativa não recebe quaisquer tipos de subsídios ou incentivos do município, dependendo única 
e exclusivamente da realização de eventos beneficentes para angariar fundos e da ajuda dos próprios educadores, educandos e de um "benfeitor" que se prontificou a pagar o aluguel do imóvel pelo período de um ano. Diante deste cenário de incertezas, o maior temor de Juliano é de que um dia ele seja obrigado a fechar as portas do Projeto e que, consequentemente, os jovens que participam das modalidades oferecidas pela iniciativa voltem à "ociosidade" que, em sua visão, é a responsável pelo "desvio" da juventude.

O outro projeto escolhido para esta investigação e que também desenvolve junto aos jovens da cidade práticas socioeducativas é o Movimento Negro, dirigido atualmente por Marcelo, de 34 anos, filho do casal fundador do Movimento. O projeto foi iniciado pela família de Marcelo no início dos anos 1980, com dois objetivos: dar continuidade às práticas de celebração da cultura afro por seus familiares e enfrentar os constantes episódios de racismo no município. O Movimento Negro fica localizado em um galpão alugado em um bairro periférico, com área de cerca de $300 \mathrm{~m}^{2}$ de construção, "momentaneamente suficiente" para acolher as mais de 100 crianças, adolescentes e jovens atendidos pelo Movimento, que têm à disposição cerca de 14 modalidades e práticas socioeducativas, entre as quais, atividades musicais, esportivas e culturais, além de ações de assistência psicológica, orientação educacional e jurídica oferecida pelos próprios dirigentes, voluntários e demais colaboradores. Além destas ações, o Movimento também cede o espaço para as crianças e jovens atendidos pelo CRAS (Centro de Referência de Assistência Social) do município, fortalecendo ainda mais os laços de envolvimento com a sociedade local.

Naturalmente, o objetivo principal do Movimento é tratar da questão étnico-racial em todos os seus aspectos, valorizando, promovendo e afirmando a cultura negra no município. Entretanto, de acordo com o próprio Marcelo, consoante a este objetivo, a educação também recebe destaque nas ações desempenhadas pelos voluntários, uma vez que todas as práticas oferecidas buscam propiciar às crianças e jovens assistidos "instruções" e "valores" que possam ajudá-los a superar as dificuldades e desafios inerentes à - nada fácil - realidade histórica das juventudes das classes menos favorecidas. Neste sentido, o coordenador nos revelou o triste fato de que 10 jovens, que já participaram do projeto e que se afastaram das atividades por motivos diversos, acabaram sendo presos por envolvimento com o tráfico, com o roubo e outras ações ilícitas. Para Marcelo, isto reafirma ainda mais a "missão" que o projeto tem para com a juventude local e a certeza de que pode realmente fazer a diferença na vida destes jovens. 
O primeiro grupo juvenil a ser referenciado neste relatório é o grupo dos skatistas, representado pelo jovem Mário, de 26 anos, vice-presidente da Associação dos Skatistas e praticante da modalidade desde os 14 anos. Trabalha em uma loja de materiais esportivos especializada em skate, que também funciona como "sede" da Associação e que fica localizada em uma praça na região central do município sul-mineiro. A loja é propriedade de um conhecido fomentador do esporte no município e um dos grandes apoiadores do evento semestral de Hip Hop. A associação visa dar visibilidade e legitimidade ao esporte, além de ser o órgão responsável por fomentar os campeonatos e de "cadastrar" os praticantes da modalidade. Segundo o jovem entrevistado, são mais de 200 skatistas cadastrados. O local de "concentração" dos praticantes nos finais de semana fica localizado na mesma praça central onde ocorre o evento de Hip Hop. Na praça há uma "pista improvisada" com alguns obstáculos como rampas, corrimões, degraus e caixotes, e é neste espaço que diversos jovens e até mesmo adultos se encontram para praticar o esporte e fazer suas manobras.

Mário revela que os maiores objetivos da Associação são"fomentar a cultura do esporte e, através do skate, atingir os 'lugares' não alcançados pelo poder público", no intuito de tirar a juventude da criminalidade e das drogas, oferecendo uma prática esportiva saudável como opção para o dispêndio de suas energias. O grupo de skatistas é composto por jovens de todas as idades e não há uma diferenciação formal entre "professor e aluno", mas é natural que os "mais experientes" assumam o papel de "tutores" encarregados de ensinar as "pegadas" e manobras do skate aos iniciantes. Os praticantes escolhem um "obstáculo", que pode ser uma rampa, um corrimão ou então um caixote especialmente feito para a prática, ou mesmo os equipamentos urbanos da cidade, como escadas, banquetas e meios-fios das calçadas da praça próxima à sede da Associação. Os "velhacos" (experientes) abrem a "série" de manobras e os demais vão logo em seguida, um de cada vez ou simultaneamente, dependendo do tamanho do obstáculo. Os primeiros passam as "manhas" de como fazer as manobras. Além disto, no tempo em que os skatistas estão juntos, há uma intensa troca de experiências e de opiniões acerca não só do skate como esporte, mas também de outros assuntos ligados à juventude, como moda, festas e"rolezinhos da galera", eventos específicos e até mesmo o mundo do trabalho.

Pensando numa maneira de popularizar o esporte e contribuir com a sociedade local, Mário buscou implantar numa escola de ensino fundamental um projeto de skate, para crianças e adolescentes da instituição de ensino 
que, em contrapartida, deveriam apresentar notas satisfatórias no boletim escolar. No entanto, o projeto não conseguiu apoio nem da escola, nem do poder municipal.

Ao contrário do que aponta o pensamento corrente sobre o skate como um "esporte marginal" "sem futuro", Wellington destaca a importância que a prática deste esporte tem nos grandes centros urbanos, e enaltece o grande volume econômico que a "cultura do skate" mobiliza nestas cidades, por meio de eventos, campeonatos e vendas de materiais esportivos. Também, existem as possibilidades efetivas de que o esporte possa vir a se tornar profissão para os jovens skatistas da cidade, novamente ajudando a afastar a juventude da criminalidade e das ações ilícitas.

O próximo grupo juvenil a ser tratado são os break boys ou simplesmente $b$.boys, representado pelo jovem alfenense Luís, de 20 anos, integrante de um crew (grupo) de breakdance, a dança típica da cultura Hip Hop. Luís ingressou no grupo em 2010 e é o mais jovem dos 6 integrantes, nem todos são moradores do município. Pelo menos uma vez por mês, todos se reúnem no município pesquisado para treinar novos passos e coreografias. Realizam ensaios duas vezes por semana no barracão do Projeto Social, quando também atuam como "educadores voluntários", incumbidos de ensinar os jovens que querem aprender a arte do breakdance.

Durante a entrevista, Luís revelou que o seu maior sonho é poder viver do breakdance, mas reconhece as dificuldades de se conseguir espaço e apoio para a prática de dança urbana, uma vez que, assim como outras artes integrantes da cultura Hip Hop, o breakdance ainda é visto com maus olhos e marginalizado em relação a outras expressões corporais mais tradicionais. É por isto que Luís entende que o objetivo principal do grupo de dança é divulgar a modalidade, a fim de quebrar as barreiras e preconceitos e, ainda, representar o município nos eventos e festivais específicos do segmento.

O jovem b.boy ressalta que esta modalidade exige muita preparação física do praticante e que é necessária muita dedicação para que o educando consiga evoluir e executar de forma satisfatória a dança. Sendo assim, não bastam só os "olhos vidrados e atentos" das crianças e dos jovens que frequentam as aulas ministradas pelos educadores voluntários no projeto, é preciso muita disciplina e cumprir com certas exigências inerentes ao estilo. A primeira delas é basicamente a "disciplina alimentar e física", para que os praticantes possam ter condições corporais mínimas para realizar os movimentos. A segunda exigência é a "concentração e o compromisso com os treinos", uma vez que as coreografias são extensas e demandam tempo para serem interiorizadas. 
A terceira e última condição é a "criatividade de improvisação", pois assim como toda arte corporal, haverá situações que demandarão dos praticantes improvisos para corrigir falhas inesperadas durante a sua apresentação corporal. Todas essas condições implicam em uma série de mudanças radicais no estilo de vida e muita disciplina aos jovens aspirantes a b.boys, o que aos olhos de Luís é um processo duplamente positivo, tanto pela expressão da arte por si mesma, quanto por poder "afastar a molecada do caminho errado" (entenda-se aqui, o caminho do crime e das drogas).

O último jovem a ser entrevistado é Carlos, representante do grupo juvenil dos rappers e conhecido MC (Master of Ceremony), termo da cultura Hip Hop que trata do sujeito responsável pela sua parte musical. Carlos tem 22 anos e também é natural do município, residindo em um bairro periférico popularmente conhecido como "perigoso", devido ao tráfico de drogas. 0 jovem cantor traz em suas rimas um pouco da dura realidade de viver em um bairro de periferia, destacando os problemas sociais típicos dos subúrbios. Carlos, apesar da carreira relativamente nova, já tem seu trabalho reconhecido na cidade e em eventos externos. Afirma que a música foi responsável por tirá-lo do "caminho errado"e, ao mesmo tempo, por renovar suas esperanças num futuro melhor para si mesmo e para a sua família.

O jovem pratica o rap em sua própria casa todos os dias e, uma vez por semana, especialmente às sextas-feiras à noite, com um grupo de outros jovens rappers, na praça central do município. Lá os jovens travam aquilo que eles chamam de "batalha de sangue", que consiste em um duelo entre dois rappers para ver qual deles consegue "tirar" (superar, humilhar) o outro e se destacar na arte da improvisação. Todavia, Carlos ressalta que sua especialidade é o "rap consciência", ou melhor, a sequência de rimas que trazem experiências de vida, críticas sociais e mensagens positivas e, por isto, explica que frequenta estes encontros mais para prestigiar seus pares e trocar materiais e ideias sobre novas músicas, aproveitando também para fortalecer os contatos com outros jovens aspirantes a rappers.

O rap é meio de enorme relevo utilizado pelos artistas das camadas populares para reivindicar as suas demandas e fazer as críticas diretas à sociedade, denunciando de forma contundente seus problemas e trazendo suas insatisfações e angústias. É um meio também para "extravasar a alma", afirma Carlos. Segundo o jovem rapper, atualmente os conteúdos propagados pelos grandes meios de comunicação de massa são extremamente "danosos" para as crianças e adolescentes, visto o alto volume de informações "negativas e sensacionalistas" que "mais querem fazer dinheiro e prender a atenção das 
pessoas do que oferecer a elas conteúdos que possam mudar para melhor as suas vidas". Neste sentido, Carlos busca oferecer, por meio de suas letras e composições, mensagens que possam ajudar as pessoas a "criarem uma nova consciência" e, assim, transformarem a sua realidade.

Carlos ressalta que a cultura Hip Hop se caracteriza como um grande movimento de aprendizado coletivo, no qual "todos se ajudam de alguma forma", pois "todo mundo sempre tem algo a ensinar". Isto parece se confirmar tanto nos eventos e festivais em que o jovem participa quanto no próprio encontro para as "batalhas de sangue": por um lado, Carlos ensina os mais novatos acerca das técnicas de improvisação, a como mensurar as métricas de rima e como utilizar os programas e softwares de mixagem; por outro, o jovem $M C$ busca aprender com seus colegas de batalha sobre novos temas e novas tendências musicais que possam ser somadas ao seu repertório. $\mathrm{O}$ resultado disso é a cristalização de um duplo movimento de aprendizagem e ensino que unifica e fortalece ainda mais a cultura do Hip Hop.

\section{DIMENSÕES EDUCATIVAS DAS PRÁTICAS CULTURAIS NOS PROJETOS E GRUPOS}

Uma primeira constatação é a de que os projetos sociais e os grupos juvenis pesquisados mantêm, em quase todos os casos, muitas relações entre si, constituindo uma série de redes informais, ou circuitos jovens, nos termos de Magnani (2005). O Movimento Negro, ao menos com os dados levantados, é o único que não faz parte destas redes. Graças ao Projeto Social e ao evento cultural de Hip Hop, entretanto, se articulam em um circuito o próprio Projeto Social, o grupo de b.boys, a Associação de Skatistas e os rappers.

Os diferentes graus de formalidade dos grupos não impedem a formação destes circuitos, ao contrário. Em relação à formalização, esperava-se, inicialmente, encontrar uma dualidade, organizações mais institucionalizadas versus grupos juvenis bastante informalizados e fluidos. Entretanto, mais que uma dualidade, encontrou-se um continuum, que vai da maior formalidade à maior informalidade. $O$ grupo mais formalizado é o Movimento Negro, organização que possui parcerias oficiais com o poder municipal, compondo a sua rede socioassistencial. Entre ele e o menos formalizado e mais fluido grupo de rappers, está o Projeto Social (que anseia por se formalizar como uma ONG), a Associação dos Skatistas (coletivo de skatistas que conservava parte importante da fluidez dos agrupamentos por afinidade) e o grupo de b.boys (grupo de amigos que se reúnem para ensaiar, ansiando pela 
profissionalização, mas que ao mesmo tempo atuam como educadores no Projeto Social). Ainda a respeito da formalização, percebe-se um movimento em direção à ela, desejada mais fortemente pelo Projeto Social, latente na Associação dos Skatistas.

Há de se citar que outros sujeitos fazem parte daquelas redes, como a loja de materiais esportivos, importante lócus articulador das práticas de skate. Também, os estudantes universitários que participam da organização do evento de Hip Hop, articulando o mundo universitário, o da suposta "cultura de elite", com os jovens das camadas trabalhadoras e sua "cultura popular". Rompe-se, assim, o suposto isolamento entre cultura popular e cultura de elite.

Mas também há uma negação da ruptura entre cultura popular "autêntica" e cultura "de massa". Trata-se da importância da cultura Hip Hop e de outra prática cultural supostamente forasteira e trazida pela indústria cultural, o skate, para a expressão social de jovens diversos na cidade e como conteúdos de práticas socioeducativas. O Hip Hop e o skate vêm a ser expressão cultural forte dos setores juvenis das classes populares no Brasil.

Em relação ao conteúdo das práticas culturais dos projetos, há de se citar a predominância da arte (dança e música), das artes marciais e do esporte. Nos projetos sociais, há a pacífica convivência entre elementos de diferentes origens culturais. Além da cultura Hip Hop de origem norte-americana, encontram-se as artes marciais de origem "oriental" (jiu jitsu, muay thay, tae kwon-do e karatê), práticas culturais de origem afro-brasileira (capoeira, a música mojuba e as danças zumba, jongo e maculelê) e esportes tradicionais (futebol, xadrez e ginástica) e não tão tradicionais no Brasil (o rugby). Apesar da mistura, se percebe que há predominância de práticas de origem afro no Movimento Negro - ainda que convivam com práticas como artes marciais "orientais" e esportes diversos. A se relembrar que a cultura Hip Hop é originalmente expressão das camadas populares negras norte-americanas, pode se afirmar a forte presença dos elementos culturais negros (de origem norte-americana ou brasileira) nas práticas culturais dos jovens na cidade.

As entrevistas trouxeram grande riqueza de dados a respeito de conteúdos culturais de práticas educativas e/ou de dimensões educativas de práticas culturais, tendo destaque as dos grupos mais informais, a Associação dos Skatistas, os b.boys e os rappers, trazendo dados profícuos em relação ao potencial criativo destas ações.

Nos discursos dos entrevistados, o recurso ao paradigma da inclusão social foi marcante em quase todas as entrevistas, exceto a do jovem rapper. 
Quando trataram dos objetivos de suas práticas, os entrevistados tenderam a dar importância à "inclusão social", especialmente nos projetos socioeducativos. Ou seja, a maior formalidade do grupo tendeu a reforçar o discurso da inclusão social, inclusive porque se trata do paradigma hegemônico no campo das práticas socioeducativas, e seu uso pode habilitar o aspirante a participar das redes socioassistenciais ou a se institucionalizar como uma ONG. Quando se refere a adolescentes e jovens, este paradigma tende a tratar da necessidade de "afastar os jovens das ruas" e dos riscos da ociosidade. Mobiliza-se, então, a imagem do "jovem como problema", associada à ideia da inerente fragilidade do jovem diante da atração da rua e do risco do ócio. (DAYRELL, 2003). Há mesmo a ideia de que o projeto social é salvaguarda dos jovens populares (FERNANDES, 2012), claramente expressa nas entrevistas com os gestores do Projeto Social e do Movimento Negro.

Por outro lado, estas iniciativas também colaboram para a efetivação e a promoção dos direitos ao acesso cultural, ao desenvolvimento artístico, ao convívio humano, às interfaces entre as políticas públicas de educação, cultura, esporte, lazer, cidadania e assistência social (CRAS). Além de, como destaca o coordenador do Movimento Negro, servem para a prevenção à violação dos direitos.

A Associação dos Skatistas e os b.boys também articularam o paradigma da inclusão àquela imagem do "jovem problema" em seus discursos. No caso da Associação dos Skatistas, afirma o entrevistado que o fomento à cultura do skate ajudaria a tirar os jovens do caminho das drogas, especialmente porque servia para consumir de modo saudável as energias dos jovens. $\mathrm{Na}$ fala do b.boy entrevistado, as exigências físicas e comportamentais do break dance também são considerados úteis ao promover mudanças no estilo de vida dos jovens, afastando-os do crime e das drogas.

O discurso hegemônico da inclusão tende a instrumentalizar as práticas culturais em torno de uma ideologia que aponta para a culpabilização do próprio "excluído", considerado responsável por sua condição por lhes faltarem recursos, habilidades e competências que permitiriam sua "inclusão" no mercado de trabalho e no mundo público (GROPPO et al., 2013). Tal é sua força, que ele apareceu, ainda que de modo secundário no caso dos b.boys, mesmo nos grupos mais informais pesquisados.

Entretanto, além da anunciada riqueza maior das práticas culturais nos grupos informais, tendeu a ser forte neles o ideal da prática da arte ou do esporte como fim em si mesmo, ou seja, valorizou-se a performance. Ao lado disto, o anseio pela profissionalização, tanto do próprio entrevistado quanto 
de outros jovens envolvidos com a prática cultural: cadastrar e concentrar os praticantes do skate, a profissionalização do grupo de dança e a divulgação das práticas.

No caso do jovem rapper, adepto do "rap consciência", foi marcante o objetivo de crítica social e conscientização por meio da música. Ainda, o confronto com as mensagens danosas da mídia de massa.

Pudemos observar que o discurso do Movimento Negro sobre os seus objetivos pode ser associado à conscientização tão valorizada pelo jovem rapper. Entretanto, quando o entrevistado trata dos objetivos educacionais do Movimento, a educação é tratada como "instrução" de "valores" para superar os desafios da realidade, bem como "missão" de afastar os jovens do perigo das ruas e da ociosidade. Com isto, aproximou-se antes ao gestor do Projeto Social, que definiu que um dos seus objetivos era oferecer um "ambiente saudável" de formação moral aos jovens.

Após tratar dos objetivos educacionais expressos por estas práticas culturais, cabe tratar das "metodologias", "estratégias" ou formas educativas utilizadas. Como se anunciou, os grupos mais informais, skatistas, b.boys e rappers, trouxeram, por meio de seus entrevistados, um repertório maior de estratégias e práticas educativas, ainda que os entrevistados do Projeto Social e do Movimento Negro também atuem como educadores nas oficinas.

As oficinas dos projetos de caráter socioeducativo tendem a seguir modelo já "clássico" da educação não formal, a saber, educadores voluntários apresentam proposta de oficina cultural, ou são convidados pelos gestores. Os jovens aderem segundo seus interesses ao rol de oficinas oferecidas. As oficinas e a participação do educador tendem a ter duração pequena, regidas pela informalidade do contrato e pela disponibilidade instável de recursos. Enfim, tendem, ao menos nos últimos anos, a ser absorvidas pelo paradigma da inclusão social, em que são menos importantes a performance ou o prazer de praticar a arte ou esporte, e mais relevantes os supostos efeitos sociais de "afastar os jovens das ruas e da ociosidade", livrando-os das drogas e do mundo do crime (GROPPO, 2012).

Já os grupos mais informais tenderam a se concentrar em uma única atividade, bem como considerar como prioritária a sua performance, mas sem deixar de se influenciar pelo discurso hegemônico da "inclusão dos excluídos". Como visto, suas narrativas trazem mais dados sobre os processos educativos ativados.

Tanto entre os skatistas, mas principalmente entre os rappers, não há separação formal entre educadores e educandos, ainda que os iniciantes 
procurem aprender com os mais experientes sobre novos elementos de sua prática. Mas não há "aulas", os iniciantes praticam skate ou o Hip Hop ao lado dos mais experientes. Entre os skatistas, os mais experientes iniciam primeiro a série de manobras, seguidos dos demais. Entre os rappers, os encontros semanais na praça promovem as "batalhas de sangue" e a intensa troca de contatos, materiais e ideias. A imagem do Hip Hop como o de um movimento de aprendizado coletivo, trazido pelo jovem rapper, é recorrente (MENDONÇA; LEITE, 2013), para demonstrar que lá, todos ensinam e aprendem coletivamente.

O skatista entrevistado narrou também sua frustrada tentativa de implementar um projeto de skate nas escolas municipais, reclamando dos preconceitos ainda fortes em relação ao esporte radical. Preconceitos em relação à cultura Hip Hop também foram narrados pelos b.boys, mas o seu grupo de dança conseguiu espaço, no Projeto Social, para realizar oficinas de break dance, uma educação não formal. Este caso ilustra como tendem a ser contratados os educadores não formais e compostas as oficinas dos projetos socioeducativos, por meio do contato com grupos culturais informais que são experts em sua prática, cujo reconhecimento é mais tácito que formal (em geral, dispensando certificação ou diploma) (GEBER, 2010). Graças a isto, o b.boy entrevistado, também oficineiro do Projeto Social, foi capaz de sistematizar melhor a estratégia educativa do grupo, em torno daquelas três exigências corporais e comportamentais. Por outro lado, sua entrevista ilustrou a atração, típica da institucionalização dos projetos socioeducativos, pelo paradigma da inclusão, tornado verdadeiro "senso comum" deste setor.

Como pressuposto dos autores, prevíamos encontrar uma relação direta entre projeto social e educação não formal, bem como entre grupo juvenil e educação informal. Mas estas relações não foram sempre tão evidentes, ainda que sejam tendências importantes. Esta relativização das relações se relaciona a outra hipótese já frustrada, narrada acima, quando não se constatou que organizações formais e coletivos informais compusessem uma dualidade.

Algumas práticas parecem tipicamente informais, no que se refere a processos educativos, como as conversas cotidianas, as "batalhas de sangue" e as performances de skate. Mas estas últimas têm um roteiro definido em que transpare uma intenção pedagógica: cada série é iniciada pelos skatistas mais experientes, os "velhacos". Quanto aos ensaios do grupo de break dance, eles vieram a se tornar oficinas de dança no Projeto Social, combinando a educação informal com a educação não formal, ou, antes, revelando a origem 
informal de muitas práticas educativas que se tornam não formais em projetos socioeducativos (PINHEIRO, 2015).

Tornando este campo das práticas culturais juvenis, em suas dimensões educativas, ainda mais complexo, há de se recordar a participação de estudantes universitários na organização do evento de Hip Hop, com o que mobilizam grupos juvenis informais de dança e música no município.

\section{CONSIDERAÇÕES FINAIS}

Neste artigo, objetivamos compreender as práticas culturais dos jovens urbanos, em uma cidade do interior de Minas Gerais, e analisar as suas dimensões educativas, partindo do suposto de que os jovens são sujeitos ativos e criadores. Assim, buscamos observar e interpretar as práticas culturais dos sujeitos populares realmente existentes, considerando a "cultura popular" como as experiências vividas concretamente pelas camadas populares ou classes trabalhadoras. Entre estes sujeitos, os jovens das classes trabalhadoras dos campos e das cidades.

Aqui, neste texto, buscamos contemporaneizar a noção de práticas culturais populares, em especial por meio do esforço em inserir os jovens das camadas populares como seus ativos sujeitos criadores. Também, evidenciar a multiplicidade das fontes das práticas culturais populares, o que é ainda mais marcante nas culturas juvenis (e não apenas as dos jovens das classes trabalhadoras). Ainda mais que os adultos, os adolescentes e jovens indicam não ter preocupação com a origem das fontes das práticas e realizam a reapropriação criativa em prol de suas necessidades e interesses cotidianos.

Em seguida, apresentamos as noções de educação informal e educação não formal como tipos ideais ou categorias a-históricas de análise, capazes de ilustrar as dimensões educativas das práticas culturais dos jovens das camadas populares do município sul-mineiro investigado. Durante a interpretação, contudo, a hipótese da relação intrínseca entre educação não formal e projetos socioeducativos, bem como a hipótese equivalente da ligação da educação informal aos grupos juvenis fluidos, não se confirmaram plenamente. Eram apenas tendências relevantes, ilustradas pelo caso do grupo de b.boys, que sistematizou suas estratégias informais de reprodução dos saberes do breakdance (típicas dos seus ensaios), de modo que pudessem planejar estes saberes como conteúdos e habilidades ensinados, de modo não formal, em oficina no Projeto Social. 
Quase todos os grupos e organizações pesquisados articulavam-se entre si, bem como com outros atores sociais, como os organizadores do evento local de Hip Hop, a universidade (por meio dos seus estudantes, organizadores deste evento) e uma loja de materiais esportivos. Criaram um circuito jovem (MAGNANI, 2005), o qual quebra a suposta dualidade entre organizações formalizadas e coletivos juvenis fluidos, configurando um interessante continuum de posições não estanques e, mais ainda, um relevante trânsito entre sujeitos educadores, práticas culturais e ações educativas informais e não formais.

Há, contudo, o risco de instrumentalização de práticas culturais juvenis em prol de objetivos extra-culturais, em especial a "inclusão social", algo observado principalmente nas práticas e discursos dos grupos mais formalizados e em práticas educativas não formais, mas não ausente dos discursos dos coletivos juvenis fluidos. Contudo, um dado mais positivo foram os fortes sinais de que os coletivos fluidos tendem a se reunir em prol da performance da sua arte ou esporte, diferenciando-se do discurso que enfatiza apenas a necessidade de afastar os jovens do risco das ruas. Tão importante quanto este, o fato de que, principalmente a partir do protagonismo dos grupos culturais juvenis, se promove uma intensa articulação entre práticas educativas informais e não formais, marcante no caso dos jovens b.boys que se tornaram oficineiros de um projeto social.

Enfim, este trabalho nos remete à extensão universitária, ao revelar agora algo recorrente na pesquisa de campo: o entusiasmo com que o pesquisador de campo foi recebido pelos entrevistados. Eles viram, certamente, uma chance de "divulgação gratuita" de suas atividades.

É patente que a pesquisa sozinha, incluindo este artigo, não conseguirão atender a este anseio. Entretanto, consideramos necessário dar algum retorno a estes projetos e educadores. Assim podemos ir ao encontro daquele entusiasmo. Trata-se da devolutiva dos resultados da pesquisa aos gestores e educadores, por meio de encontros e/ou oficinas. Mais importante, também por meio da extensão universitária, a promoção de eventos que contemplem realmente as práticas culturais destes sujeitos, divulgando-as e contribuindo com sua legitimação. 


\section{NON-FORMAL AND INFORMAL EDUCATIONAL DIMENSIONS OF YOUTH CULTURAL PRACTICES IN THE CITY}

ABSTRACT: The article systematizes data collected in field research - with observations and interviews - about cultural practices of young people of the lower classes in two socio-educative projects and three informal groups, in a county in Minas Gerais, Brazil. The article deals with the educational dimension of these practices, in particular its objectives and methodologies, based on non-formal education and informal education notions. It is possible to notice the wealth of youth cultural practices, the diversity of references and the strength of black cultures, such as the Hip-Hop and African-Brazilian arts. In addition, the combination of more or less formal strategies of education and the creation of circuits between socio-educative projects and youth groups.

KEYWORDs: Non-formal education. Youth culture. Youth projects. Hip-Hop.

\section{DIMENSIONES EDUCATIVAS NO FORMALES E INFORMALES DE LAS PRÁCTICAS CULTURALES JUVENILES EN LA CIUDAD}

Resumen: El artículo analiza los datos recogidos en la investigación de campo - con observaciones y entrevistas - acerca de las prácticas culturales de jóvenes de niveles sociales populares en dos proyectos socioeducativos y tres grupos informales, en un municipio del Sur de Minas Gerais, Brasil. El artículo enfoca la dimensión educativa de esas prácticas, en particular, de sus objetivos y procedimientos, tomando como referencia nociones de educación no formal y educación informal. Se constata la riqueza de las prácticas culturales juveniles, la diversidad de referencias y la fuerza de las culturas negras, con el Hip Hop y las artes afro-brasileños. Igualmente, la combinación entre estrategias más o menos formales de educación y la creación de redes entre proyectos socioeducativos y grupos juveniles.

Palabras-Clave: Educación no formal. Educación informal. Cultura juvenil. Proyectos juveniles. Hip Hop.

\section{NOTAS}

1) Como referências adicionais sobre educação não formal, destacamos: Coombs (1986), Brennan (1997), Gohn (1999), Trilla (1996), Gadotti (2005) e Spósito (2008). Sobre o avanço da forma escolar, ver Saviani (2009).

2) Aqui, e ao longo do artigo, serão usados nomes fictícios para se referir aos projetos socioeducativos, aos grupos juvenis e aos sujeitos entrevistados. 


\section{REFERÊNCIAS}

ALFONSO, A. J. Os lugares da educação. In: SIMSON, Olga Rodrigues de Moraes von; PARK, Margareth Brandini; FERNANDES, Renata Sieiro (Org.). Educação não formal: cenários da criação. Campinas: Editora da Unicamp, Centro de Memória, 2001, p. 29-38.

BRENNAN, B. Reconceptualizing non-formal education. Internacional Journal of Lifelong Education, v. 16, n. 3, 1997, p. 185-200.

COOMBS, P. H. A crise mundial da educação. São Paulo: Perspectiva, 1986.

CRUZ, R. R. Emergencia de culturas juveniles. Estrategias del desencanto. Buenos Aires: Norma, 2000.

DAYRELL, J. O jovem como sujeito social. Revista Brasileira de Educação, Rio de Janeiro, n. 24, p. 40-52, set./dez. 2003.

. O rap e o funk na socialização da juventude. Educação e Pesquisa, São Paulo, v. 28, n. 1, p. 117-136, jan./jun. 2002.

EAGLETOWN, T. A ideia de cultura. Lisboa: Temas e Debates, 2003.

FERNANDES, R. S. Formação de educadores e o trabalho na educação não formal: juventude, cidade e tempo livre. Comunicações, Piracicaba, ano 19, n. 1, p. 57-70, 2012.

GADOTTI, Moacir. A questão da educação formal/não formal. Institut International des Droits de L'enfant (Ide) Droit à l'éducation: solution à tous les problèmes ou problème sans solution? Sion (Suisse), 18 au 22 octobre, 2005. Disponível em:<http:// www.vdl.ufc.br/solar/aula_link/lquim/A_a_H/estrutura_pol_gest_educacional/ aula_01/imagens/01/Educacao_Formal_Nao_Formal_2005.pdf>. Acesso em: $18 \mathrm{fev}$. 2015.

GARCIA, V. A. Educação não-formal: um mosaico. In: Park, M. B.; Fernandes, R. S. (Org.). Palavras-chave em educação não formal. Holambra: Setembro, Campinas; CMU, 2007, p. 31-52.

GEBER, S. P. Jovens educadores no contexto de uma ação pública voltada para a juventude na periferia de Belo Horizonte. 2010. 147 f. Dissertação (Mestrado em Educação). Universidade Federal de Minas Gerais, Belo Horizonte, 2010.

GOHN, M. G. Educação não formal e cultura política: impactos sobre o associativismo do terceiro setor. São Paulo: Cortez, 1999.

GROPPO, L. A. Dos prazeres e das performances nos esportes e nas artes: considerações sobre as práticas socioeducativas para jovens das camadas populares. In: Odair Marques da Silva et al. (Org.). Pedagogia social. Animação sociocultural: um propósito da pedagogia social. São Paulo: Expressão \& Arte. 2012, p. 120-132.

et al. Sociologia da Educação Sociocomunitária: ensaios sobre o campo das práticas socioeducativas e a educação não formal. Holambra: Setembro, 2013. 
HALL, S.; JEFFERSON, T. (Org.). Resistance through rituals. Youth and subcultures in post-war Britain. Londres: Hutchinson, Birmingham: Universidade de Birmingham, 1982.

MAGNANI, J. G. C. Os circuitos dos jovens urbanos, Tempo Social: revista de sociologia da USP, São Paulo, v. 17, n. 2, p. 173-205, nov. 2005.

MENDONÇA, V. M.; LEITE, K. C. Uma análise sobre as relações entre educação, juventude e movimentos sociais: o hip Hop brasileiro. Impulso, Piracicaba, v. 23, n. 56, p. 73-85, jan.-abr. 2013.

OLIVEIRA, R. C. O Trabalho do Antropólogo. 2. ed. Brasília: Editora Paralelo 15: São Paulo: Editora Unesp, 2006.

PAIS, J. M. Lazeres e sociabilidades juvenis - um ensaio de análise etnográfica. Análise Social, v. XXV, n. 108-109, p. 591-644. 1990.

PARK, M. B.; FERNANDES, R. S.; CARNICEL, A. (Org.). Palavras-chave em educação não-formal. Holambra: Setembro, Campinas: Centro de Memória da Unicamp, 2007.

PINHEIRO, L. Identidades e individuação na prática do break: narrativa sobre as experiências de jovens do Restinga Crew. 37a Reunião Nacional da ANPEd - 04 a 08 de outubro de 2015, UFSC - Florianópolis. Disponível em: <http://37reuniao.anped. org.br/wp-content/uploads/2015/02/Trabalho-GT03-3681.pdf>. Acesso em: 10 mar. 2016.

RODRIGUES, A. T. Sociologia da Educação. 5. ed. Rio de Janeiro: DP\&A, 2004.

SILVA, C. N. O. Experiências educativas com arte e cultura: significados e sentidos das práticas no percurso biográfico de jovens de origem popular. 2012. 118 f. Dissertação (Mestrado em Educação), Universidade Federal Fluminense, Faculdade de Educação, Niterói, 2012.

SILVA, C. F. S.; CASTRO, L. R. de. Para além das fronteiras convencionais do ativismo político: a inserção de jovens em "coletivos fluidos". In: BEZERRA, H. D.; OLIVEIRA, S. M. de. Juventude no século XXI: dilemas e perspectivas. Goiânia: Cânone Editorial, 2013, p. 14-44.

SAVIANI, D. Entrevista: A educação fora da escola. Revista de Ciências da Educação, Ano XI, n. 20, 1. sem. de 2009, p. 17-27.

SPÓSITO, M. P. Juventude e educação: interações entre a educação escolar e a educação não formal. Educação \& Realidade, v. 38, n. 2, jul./dez. 2008,

TRILLA, J. La educación fuera de la escuela: ámbitos no formales y educación social. Barcelona: Ariel, 1996.

WEBER, M. A "objetividade" do conhecimento nas Ciências Sociais, In: G. COHN (Org.). Weber. Sociologia. São Paulo: Ática, 1979, p. 79-127. 
Luís Antonio Groppo: Doutor em Ciências Sociais pela Universidade Estadual de Campinas. Professor do curso de Ciências Sociais da Universidade Federal de Alfenas/MG (Unifal). Tem experiência na área de Sociologia, com ênfase em Sociologia da Educação e Sociologia da Juventude, assim como na área de História dos movimentos estudantis. Atua principalmente nos seguintes temas: juventude, movimento estudantil, sociologia da educação, educação não formal, educação sociocomunitária, práticas socioeducativas etc.

E-mail: luis.sroppo@smail.com

Enzo Michel Felipe Correia dos Santos Goussain: Bacharel em Ciências Sociais pela Universidade Federal de Alfenas. Bolsista de Iniciação Científica pela FAPEMIG (Fundação de Amparo à Pesquisa do Estado de Minas Gerais).

E-mail: enzo.soussain@outlook.com 
